\title{
Gene Polymorphisms of Novel Immunotolerant Molecule BTLA: Distribution of Alleles, Genotypes and Haplotypes in Polish Caucasian Population
}

\author{
Anna Partyka - Dariusz Woszczyk - Tomasz Strzała • Anna Szczepańska • \\ Anna Tomkiewicz • Irena Frydecka • Lidia Karabon
}

Received: 30 January 2014/ Accepted: 12 May 2014/Published online: 3 September 2014

(c) The Author(s) 2014. This article is published with open access at Springerlink.com

\begin{abstract}
B and T lymphocyte attenuator (BTLA) is one of the members of immunoglobulin superfamily which, like CTLA-4 and PD-1, is involved in down regulation of immune response. Despite the important role of BTLA in maintaining immune homeostasis, relatively little studies were devoted to the relationship of polymorphisms in the gene encoding BTLA with susceptibility to autoimmune disease and cancer. Moreover, all published works were done in Asian populations. BTLA gene is located on chromosome 3 in q13.2 and consists of five exons. The aim of this study was to investigate the alleles, genotypes and haplotypes frequency of selected BTLA gene polymorphisms in Caucasian population originating from Poland. For this study, the single-nucleotide polymorphisms (SNPs) were chosen on the basis of literature data. Additionally, the tag dSNP under linkage equilibrium $r^{2}>0.8$ and available at the National Center for Biotechnology Information (NCBI) for Caucasian population of rare alleles at a frequency greater than $5 \%$ have been chosen
\end{abstract}

A. Partyka - A. Szczepańska - A. Tomkiewicz · I. Frydecka .

L. Karabon $(\square)$

Department of Experimental Therapy, Institute of Immunology

and Experimental Therapy, Polish Academy of Science,

Weigla 12, 53-114 Wroclaw, Poland

e-mail: lkarabon@iitd.pan.wroc.pl

D. Woszczyk

Department of Hematology, State Hospital, Opole, Poland

T. Strzała

Department of Genetics, Wroclaw University of Environmental and Life Sciences, Wroclaw, Poland

L. Karabon

Department of Clinical Urology, Wroclaw Medical University, Wroclaw, Poland using the NCBI database. The ten BTLA SNPs investigated were: rs1844089, rs2705535, rs9288952, rs9288953, rs1982809, rs2633580, rs2705511, rs2705565, rs76844316, rs16859633. For all SNPs selected on the basis of literature data the significantly different distributions of genotypes between Asian and Caucasian populations were observed.

Keywords Gene polymorphism .

Co-inhibitory molecule $\cdot$ BTLA $\cdot$ Caucasian population

$\begin{array}{ll}\text { Abbreviations } \\ \text { BTLA } & \text { B and T lymphocyte attenuator } \\ \text { CD } & \text { Cluster of differentiation } \\ \text { CTLA-4 } & \text { Cytotoxic leukocyte antigen-4 } \\ \text { HVEM } & \text { Herpes virus entry mediator } \\ \text { HWE } & \text { Hardy-Weinberg equilibrium } \\ \text { IL } & \text { Interleukin } \\ \text { ITIM } & \begin{array}{l}\text { Immunoreceptor tyrosine-based inhibitory } \\ \text { motif }\end{array} \\ \text { NCBI } & \text { National Center for Biotechnology Information } \\ \text { PD-1 } & \begin{array}{l}\text { Programmed death-1 } \\ \text { SHP }\end{array} \\ & \begin{array}{l}\text { Src homology region } 2 \text { domain-containing } \\ \text { phosphatase }\end{array} \\ \text { SNP } & \text { Single-nucleotide polymorphism } \\ \text { Th } & \text { T helper cells }\end{array}$

Introduction

$\mathrm{B}$ and $\mathrm{T}$ lymphocyte attenuator (BTLA) is a suppressor molecule belonging to the immunoglobulin superfamily which, like cytotoxic leukocyte antigen-4 (CTLA-4) and programmed death-1 (PD-1), is involved in the inhibition of the immune response. BTLA shares only 9-13\% amino acid identity with CTLA- 4 and PD-1, but is structurally 
similar to them and like other co-inhibitory molecules has two immunoreceptor tyrosine-based inhibitory motifs (ITIM) in its cytoplasmic region (Watanabe et al. 2003). BTLA interaction with the ligand herpes virus entry mediator (HVEM) causes phosphorylation of tyrosine within the ITIM and their connection to protein tyrosine phosphatase SHP-1 and SHP-2, and consequently inhibition of $\mathrm{T}$-cell activation and production of cytokines interferon $\gamma$, interleukin (IL)-2, IL-4, and IL-10 (Murphy et al. 2006; Nelson et al. 2008; Sedy et al. 2005). BTLAmediated inhibition of $\mathrm{T}$-cell activation occurred during both the primary $\mathrm{CD}^{+}$and secondary $\mathrm{CD} 4^{+}$and $\mathrm{CD}^{+}$ $\mathrm{T}$-cell response, suggesting that BTLA ligation provides a constitutive inhibition signal to T cells (Otsuki et al. 2006). BTLA expression is equal on Th1 and Th2 cells (Otsuki et al. 2006).

BTLA expression in murine naive B cells is high, but its role in the activation and differentiation of $B$ cells has not been studied. BTLA expression in naive murine $\mathrm{T}$ cells is negligible, but its expression increases during T-cell activation. BTLA expression is also significant in mice thymocytes during positive selection (Watanabe et al. 2003). Moreover, BTLA is expressed by macrophages, dendritic cells and natural killer cells (Han et al. 2004). In recent years strong expression of BTLA on malignant $\mathrm{B}$ cells in patients with B-cell chronic lymphocytic leukemia has been reported in the literature (M'Hidi et al. 2009).

Because BTLA was relatively recently described in the literature, there are only a few studies that address BTLA gene polymorphisms, and most have investigated its role in susceptibility to autoimmune diseases, such as rheumatoid arthritis (Lin et al. 2006; Oki et al. 2011), systemic lupus erythematosus and type 1 diabetes mellitus (Inuo et al. 2009) and only one in risk of cancer (Fu et al. 2010).

The aim of this study was to determine allele, genotype and haplotype frequencies as well as linkage disequilibrium of selected polymorphisms in the BTLA gene.

\section{Materials and Methods}

DNA was isolated from venous blood from 417 unrelated healthy volunteers from Western Poland (172 female/245 male) according to the manual procedure for white blood cells using the QIAamp DNA Blood Mini Kit (Qiagen, Germany).

In Poland migration and nationality diversion is very small, therefore Polish cohort was homogenous. The genetic homogenization was reflected in virtually identical frequencies of $\mathrm{H}-\mathrm{Y}$ polymorphisms in different regions of Poland described by Ploski et al. (2002).
Genotyping

Nine single-nucleotide polymorphisms in the BTLA gene, rs1844089, rs2705535, rs9288952, rs9288953, rs1982809, rs2633580, rs2705511, rs76844316, rs16859633, were genotyped using the TaqMan ${ }^{\circledR}$ SNP Genotyping Assays, respectively: C__26921149_20, C__16272852_10, C_1175845_10, C__1175838_10, C__1175848_20, C__16047575_10, C__16272823_10, assay on demand, C__34010634_10, provided by Applied Biosystems (Foster City, USA). Genotyping for rs2705565 was done using TIB MOLBIOL LightSNiP assay (no. 24901301).

\section{Statistical Analysis}

The evaluation of Hardy-Weinberg equilibrium (HWE) was performed by comparing the observed and expected frequencies of genotypes using $\chi^{2}$ analysis. The haplotype frequencies for pairs of alleles were determined using the SHEsis program (http://202.120.7.14/analysis/myAnalysis. php) (Shi and He 2005). Haplotypes with frequencies lower than 0.03 were not considered. Linkage disequilibrium coefficients $r^{2}$ (values for a pair of the most common alleles at each locus) were estimated using http://202.120.7. 14/analysis/myAnalysis.php (Shi and He 2005). The $\chi^{2}$ test was used to compare categorical data between poles and other populations on the basis of literature data. Differences were considered statistically significant if $p<0.05$. For the multiple comparisons, Bonferroni multiple adjustments were employed to the level of significance.

Furthermore, to analyze ethnic relationship between the Polish and other populations [Yoruba in Ibadan, Nigeria; Japanese in Tokyo, Japan; Han Chinese in Beijing, China; CEPH (Utah residents with ancestry from northern and western Europe)], we estimated phylogenetic tree based on nine out of ten single nucleotide polymorphism (SNP) loci (rs76844316 locus was excluded because of lack of data for non-Polish populations) used in present work. The tree was created using SNP allele frequency [for Polish population data were estimated in present study and for others possessed from Hapmap database (Genbank)] with Poptree 2 (Takezaki et al. 2010) using Neigbour Joining algorithm (Saitou and Nei 1987) and $D_{\mathrm{A}}$ distance (Nei et al. 1983) as a measure of population differentiation. The tree's nodes significance was evaluated with 1,000 bootstrap analysis.

\section{Results and Discussion}

We found that each polymorphism in the BTLA gene was in HWE.

Distributions of alleles and genotypes are presented in Table 1. In five out of ten investigated polymorphisms wild 
Table 1 Distribution of alleles and genotypes of the following SNPs: rs2705511, rs1982809, rs9288952, rs76844316, rs16859633, rs9288953, rs2705535, rs1844089, rs2705565, rs2633580 (listed in the physical position order; contig NT_005612.16)

\begin{tabular}{|c|c|c|c|c|c|c|c|c|}
\hline SNP & Alternative name & $\begin{array}{l}\text { Chromosome } \\
\text { position }\end{array}$ & Location & $\begin{array}{l}\text { Major } \\
\text { allele }\end{array}$ & $\begin{array}{l}\text { Minor } \\
\text { allele }\end{array}$ & $\begin{array}{l}\text { First } \\
\text { homozygous } \\
N(\%)\end{array}$ & $\begin{array}{l}\text { Heterozygous } \\
N(\%)\end{array}$ & $\begin{array}{l}\text { Second } \\
\text { homozygous } \\
N(\%)\end{array}$ \\
\hline rs 2705511 & g. $18674625 A>C$ & 112179479 & Intragenic & A $622(74.58)$ & C $212(25.42)$ & $234(56.11)$ & $154(36.94)$ & $29(6.95)$ \\
\hline rs1982809 & g. $18677886 A>G$ & 112182740 & $3^{\prime}$ near gene & A $636(76.26)$ & G $198(23.74)$ & $245(58.89)$ & $146(34.77)$ & $26(6.24)$ \\
\hline rs9288952 & g. $18680171 G>A$ & 112185025 & $\begin{array}{l}\text { Exon } 4 \\
\quad \text { (Pro-Leu) }\end{array}$ & A $784(94.00)$ & G $50(6.00)$ & $369(88.50)$ & $46(11.02)$ & $2(0.48)$ \\
\hline rs76844316 & g.18683755T > G & 112188609 & $\begin{array}{l}\text { Exon } 4 \\
\quad \text { Asn-Thr }\end{array}$ & T $400(100)$ & $\mathbf{G} 0(0)$ & $200(100)$ & $0(0)$ & $0(0)$ \\
\hline rs 16859633 & g.18693481T >C & 112198335 & Exon 2 Ile-Val & T 400 (100) & C $0(0)$ & $200(100)$ & $0(0)$ & $0(0)$ \\
\hline rs9288953 & g. $18698398 C>T$ & 112203252 & Intron 1 & C $521(62.47)$ & T 313 (37.53) & $164(39.32)$ & $193(46.28)$ & $60(14.39)$ \\
\hline rs 2705535 & g. $18704073 C>T$ & 112208927 & Intron 1 & C 823 (98.68) & T $11(1.32)$ & $406(97.36)$ & $11(2.64)$ & $0(0)$ \\
\hline rs 1844089 & g.18712880G >A & 112217734 & Intron 1 & G 758 (90.98) & A $76(9.11)$ & $343(82.26)$ & $72(17.26)$ & $2(0.48)$ \\
\hline rs 2705565 & g. $18714482 C>T$ & 112219336 & $5^{\prime}$ near gene & C 736 (94.85) & T $40(5.15)$ & 349 (89.95) & 38 (9.79) & $1(0.25)$ \\
\hline rs2633580 & g. $18714899 C>G$ & 112219753 & $5^{\prime}$ near gene & G $759(91.23)$ & C 73 (8.77) & $346(83.17)$ & $67(16.11)$ & $3(0.72)$ \\
\hline
\end{tabular}

Table 2 Analysis of estimated haplotype frequency of SNPs rs2705511, rs1982809, rs9288952, rs9288953, rs2705535, rs1844089, rs2705565, rs2633580 in Polish population

\begin{tabular}{lllllllll}
\hline rs2705511 & rs1982809 & rs9288952 & rs9288953 & rs2705535 & rs1844089 & rs2705565 & rs2633580 & Haplotype frequency \\
\hline A & A & A & C & C & G & C & G & 0.476 \\
A & A & A & T & C & G & C & G & 0.209 \\
C & G & A & T & C & G & C & G & 0.122 \\
C & A & A & C & C & G & C & G & 0.035 \\
\hline
\end{tabular}

alleles were observed in more than $90 \%$ of the Polish population. In the case of intron polymorphism rs9288953, we observed about $40 \%$ minor allele frequency, while for rs1982809 situated in the $3^{\prime}$ near gene position and rs2705511 located in the intragenic region the minor allele frequency was about $24 \%$ in both cases. Two other polymorphisms - rs76844316, described in the literature as polymorphic in the Japanese population (Oki et al. 2011); and rs16859633, chosen on the basis of HapMap analysisseem not to be polymorphic in Poles since none of 200 genotyped volunteers were carriers of mutant alleles.

In haplotype analysis two non-polymorphic sites, rs76844316 and rs16859633, were omitted. Haplotype frequencies are presented in Table 2. Only four haplotypes were represented in the Polish population with frequency $>3 \%$. The haplotype of rs2705511A, rs1982809A, rs9288952A, rs9288953C, rs2705535C, rs1844089G, rs2705565C, rs2633580G, consisting of wild alleles appeared in almost $50 \%$.

The linkage equilibrium analysis showed that rs 1844089 and rs2633580 as well as rs9288952 and rs2705565 were in strong linkage disequilibrium $\left(r^{2}=0.90\right.$ and $r^{2}=0.81$, respectively). Moreover, the following pairs were in moderate linkage disequilibrium expressed by $r^{2}>0.5$ : rs1844089 and rs9288952, rs9288952 and rs2633580, rs1982809 and rs2705511, rs1844089 and rs2705565, rs2633580 and rs2705565 (Table 3).

Comparison with data available from HapMap (http:// hapmap.ncbi.nlm.nih.gov/cgi-perl/gbrowse/hapmap24_ B36/\#search 2013) for different populations is presented in Table 4. Our results are similar to those reported in HapMap for a Caucasian population except for rs2705565. However, distribution of alleles in almost all investigated SNPs varies for Asian populations-Han Chinese and Japanese.

Phylogenetic tree obtained in our study showed clear division into three clades (Fig. 1). First clade was consisted of Polish and Caucasian (CEU) populations, second with Japanese (JPT) and Chinese (CHB) populations and third one with African population (YRI). Obtained results indicated that Polish population is ethnically and genetically closest to Caucasian population (represented in this analysis by CEPH population which was derived from European ancestors). Furthermore, both Caucasian populations were different from Japanese and Chinese populations (which were closest to each other) and all aforementioned populations were distinct from African population. 
Table 3 Linkage disequilibrium coefficients $r^{2}$ values for pairs of the investigated SNPs

\begin{tabular}{|c|c|c|c|c|c|c|c|}
\hline$r^{2}$ & rs1982809 & rs9288952 & rs9288953 & rs2705535 & rs1844089 & rs 2705565 & rs 2633580 \\
\hline rs 2705511 & 0.596 & 0.045 & 0.064 & 0.003 & 0.023 & 0.025 & 0.026 \\
\hline rs1982809 & - & 0.123 & 0.089 & 0.020 & 0.085 & 0.106 & 0.082 \\
\hline rs9288952 & - & - & 0.029 & 0.169 & 0.552 & 0.810 & 0.578 \\
\hline rs9288953 & - & - & - & 0.008 & 0.051 & 0.032 & 0.057 \\
\hline rs 2705535 & - & - & - & - & 0.133 & 0.265 & 0.139 \\
\hline rs 1844089 & - & - & - & - & - & 0.548 & 0.900 \\
\hline rs2705565 & - & - & - & - & - & - & 0.575 \\
\hline
\end{tabular}

$r^{2}$ values with strong $\mathrm{LD}>0.8$ are given in bold

Table 4 Summary data on the frequency of alleles for BTLA gene polymorphisms in the Polish population from the present study and in other populations based on data from HapMap 2013 (http://hapmap.ncbi.nlm.nih.gov/cgi-perl/gbrowse/hapmap24_B36/\#search)

\begin{tabular}{|c|c|c|c|c|c|c|c|c|c|c|c|c|}
\hline \multirow[t]{2}{*}{ SNP } & \multirow{2}{*}{$\begin{array}{l}\text { Major } \\
\text { allele }\end{array}$} & \multirow{2}{*}{$\begin{array}{l}\text { Minor } \\
\text { allele }\end{array}$} & \multicolumn{2}{|c|}{ Poles present study } & \multicolumn{2}{|c|}{ HapMap CEU } & \multicolumn{2}{|c|}{ HapMap YRI } & \multicolumn{2}{|c|}{ НарМар JPT } & \multicolumn{2}{|c|}{ HapMap CHB } \\
\hline & & & $\begin{array}{l}\text { Major } \\
\text { allele }\end{array}$ & $\begin{array}{l}\text { Minor } \\
\text { allele }\end{array}$ & $\begin{array}{l}\text { Major } \\
\text { allele }\end{array}$ & $\begin{array}{l}\text { Minor } \\
\text { allele }\end{array}$ & $\begin{array}{l}\text { Major } \\
\text { allele }\end{array}$ & $\begin{array}{l}\text { Minor } \\
\text { allele }\end{array}$ & $\begin{array}{l}\text { Major } \\
\text { allele }\end{array}$ & $\begin{array}{l}\text { Minor } \\
\text { allele }\end{array}$ & $\begin{array}{l}\text { Major } \\
\text { allele }\end{array}$ & $\begin{array}{l}\text { Minor } \\
\text { allele }\end{array}$ \\
\hline rs2705511 & A & $\mathrm{C}$ & 0.746 & 0.254 & 0.670 & 0.330 & 0.650 & 0.350 & 0.216 & 0.784 & 0.267 & 0.733 \\
\hline rs1982809 & A & $\mathrm{G}$ & 0.763 & 0.237 & 0.733 & 0.267 & 0.683 & 0.317 & 0.170 & 0.830 & 0.233 & 0.767 \\
\hline rs9288952 & A & G & 0.940 & 0.060 & 0.974 & 0.026 & 0.110 & 0.890 & 0.716 & 0.284 & 0.733 & 0.267 \\
\hline rs76844316 & $\mathrm{T}$ & G & 1 & 0 & - & - & - & - & - & - & - & - \\
\hline rs16859633 & $\mathrm{T}$ & C & 1 & - & 1 & 0 & 0.983 & 0.017 & 1 & 0 & 1 & 0 \\
\hline rs9288953 & $\mathrm{C}$ & $\mathrm{T}$ & 0.625 & 0.375 & 0.658 & 0.342 & 0.992 & 0.008 & 0.420 & 0.580 & 0.456 & 0.544 \\
\hline rs2705535 & $\mathrm{C}$ & $\mathrm{T}$ & 0.987 & 0.013 & 0.982 & 0.018 & 0.839 & 0.161 & 0.822 & 0.178 & 0.798 & 0.202 \\
\hline rs 1844089 & G & A & 0.910 & 0.090 & - & - & 0.342 & 0.658 & 0.739 & 0.261 & 0.756 & 0.244 \\
\hline rs 2705565 & $\mathrm{C}$ & $\mathrm{T}$ & 0.949 & 0.051 & 0.942 & 0.058 & - & - & 0.818 & 0.182 & 0.825 & 0.175 \\
\hline rs 2633580 & G & $\mathrm{C}$ & 0.912 & 0.088 & 0.940 & 0.060 & 0.347 & 0.653 & 0.739 & 0.261 & 0.756 & 0.244 \\
\hline
\end{tabular}

CEU CEPH (Utah residents with ancestry from northern and western Europe), YRI Yoruba in Ibadan, Nigeria, JPT Japanese in Tokyo, Japan, CHB Han Chinese in Beijing, China

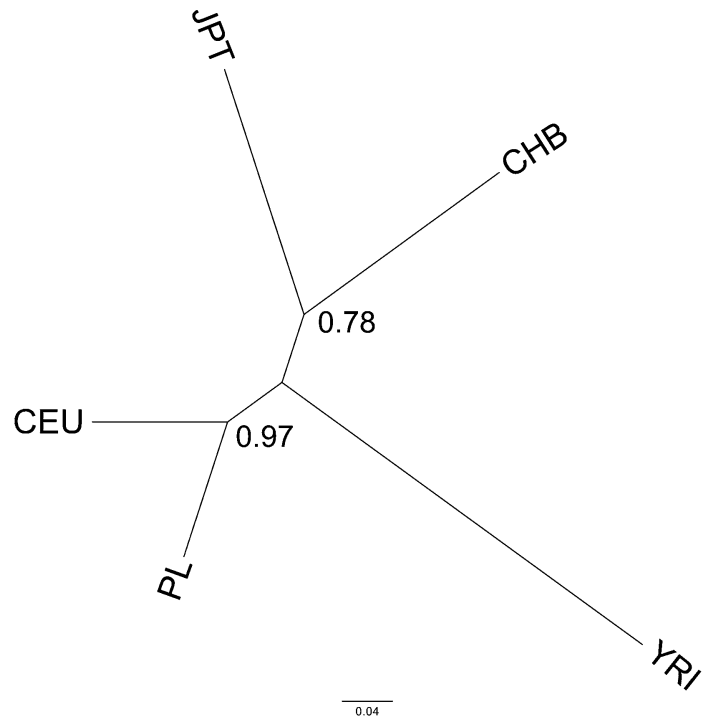

Fig. 1 Phylogenetic tree presenting relationship between five ethnically different human populations (CEU CEPH (Utah residents with ancestry from northern and western Europe); YRI Yoruba in Ibadan, Nigeria; JPT Japanese in Tokyo, Japan; $C H B$ Han Chinese in Beijing, China) created with SNP frequency data. Numbers along nodes are bootstrap values
On the basis of a literature survey (Fu et al. 2010; Lin et al. 2006; Oki et al. 2011), we compared the genotype frequency for four SNPs (Fig. 2). The SNP rs9288952 was the most commonly investigated and there were data available from Chinese, Taiwanese and Japanese population. This polymorphism is situated in exon 4 and is a missense mutation. The nucleotide exchange causes amino acid residue change Pro-Leu in position 219. The literature data indicate that this SNP is associated with susceptibility to rheumatoid arthritis in the Japanese population and with breast cancer risk in Chinese women. We found statistically significant differences in genotype distribution between Polish and Chinese as well as Polish and Taiwanese populations (Fig. 2). For two other polymorphisms, rs1844089 and rs2705535, connected with breast cancer risk, only data from the Chinese population (Fu et al. 2010) were available. We found statistically significant differences in distribution of genotypes between Polish and Chinese populations.

The rs9288953 SNP was investigated in a Japanese population as a candidate SNP for type 1 diabetes mellitus 


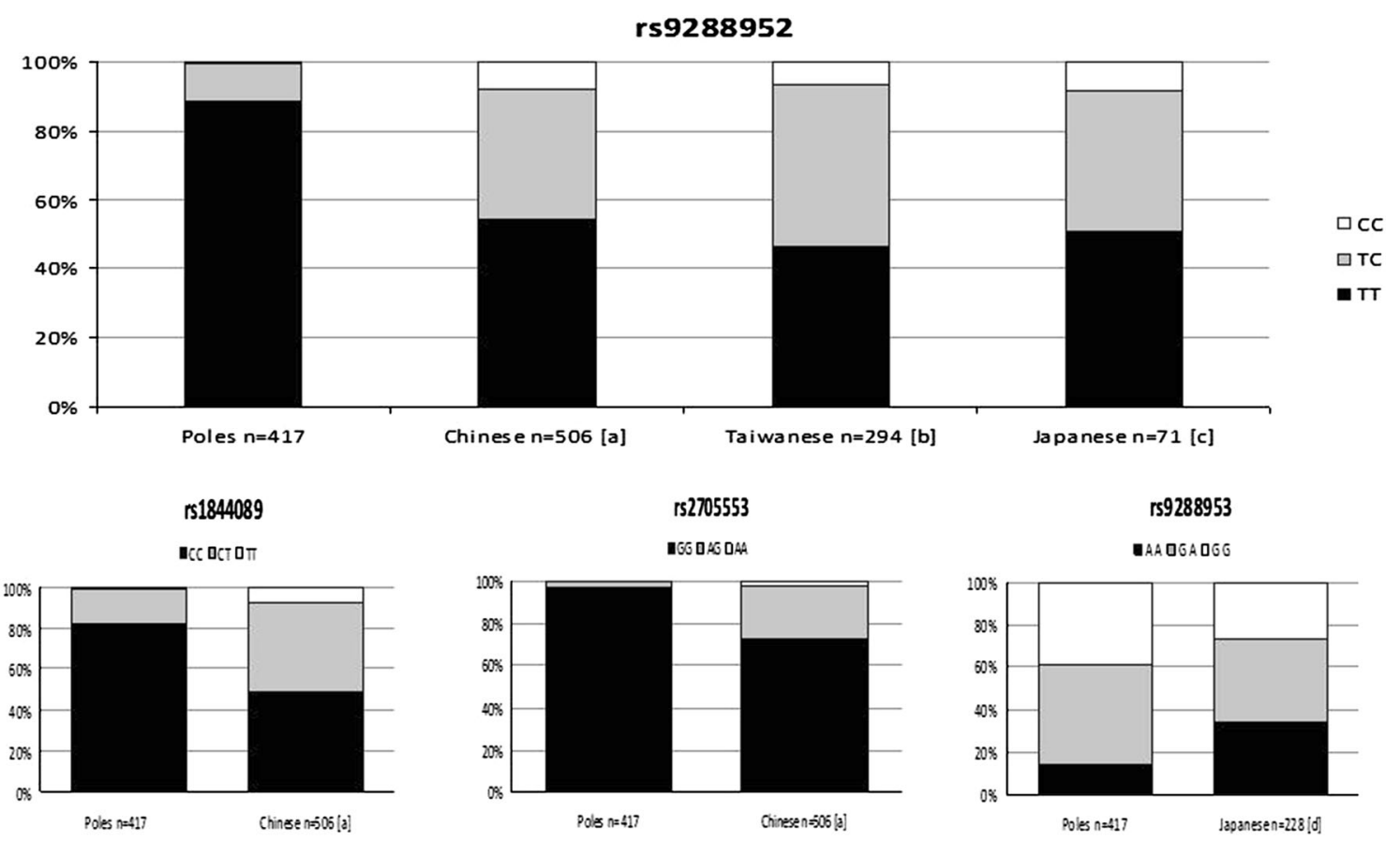

Fig. 2 Distribution of genotypes for BTLA gene polymorphisms in different populations on the basis of literature survey. [a] $\mathrm{Fu}$ et al. (2010), [b] Lin et al. (2006), [c] Oki et al. (2011), [d] Inuo et al. (2009). Distributions of genotypes were significantly different

or systemic lupus (Inuo et al. 2009). The study showed no associations of that polymorphism with selected autoimmune diseases. In our comparison, we found statistically different distribution of genotypes between Polish and Japanese healthy volunteers. Of note, the genotype distributions reported in this study for controls were not in HWE.

Recent papers have indicated the key role of the HVEM-BTLA pathway in inflammation, autoimmunity and infection immunity (del Rio et al. 2010; Shui et al. 2011) as well as immune tolerance, especially in aspects of allotransplantation (Hobo et al. 2012).

On the other hand, it was shown in an animal model that polymorphisms existing in the mouse btla gene were associated with differences in the Ig domain and BTLA expression pattern between different mouse strains and cell lines (Han et al. 2004; Hurchla et al. 2005). Therefore, polymorphisms existing in the human BTLA gene might influence the predisposition to immune-related disease. This work contributes to the overall knowledge of the presence and frequency of occurrence of allelic variants in the Caucasian population precisely in Polish population.

Acknowledgments This work was supported by grants from the Polish Ministry of Science and Higher Education (N N403 172339, N N402 682040 and N N402 454339). between Polish population and others Asian population compared separately, and compared with Asian population together ( $p<0.0000025$; with Bonfrerroni corrections)

Open Access This article is distributed under the terms of the Creative Commons Attribution License which permits any use, distribution, and reproduction in any medium, provided the original author(s) and the source are credited.

\section{References}

del Rio ML, Lucas CL, Buhler L et al (2010) HVEM/LIGHT/BTLA/ CD160 cosignaling pathways as targets for immune regulation. J Leukoc Biol 87:223-235

Fu Z, Li D, Jiang W et al (2010) Association of BTLA gene polymorphisms with the risk of malignant breast cancer in Chinese women of Heilongjiang Province. Breast Cancer Res Treat 120:195-202

Han P, Goularte OD, Rufner K et al (2004) An inhibitory Ig superfamily protein expressed by lymphocytes and APCs is also an early marker of thymocyte positive selection. J Immunol 172:5931-5939

Hobo W, Norde WJ, Schaap N et al (2012) B and T lymphocyte attenuator mediates inhibition of tumor-reactive CD8+ T cells in patients after allogeneic stem cell transplantation. J Immunol 189:39-49

Hurchla MA, Sedy JR, Gavrieli M et al (2005) B and T lymphocyte attenuator exhibits structural and expression polymorphisms and is highly Induced in anergic CD4+ $\mathrm{T}$ cells. J Immunol 174:3377-3385

Inuo M, Ihara K, Matsuo T et al (2009) Association study between Band T-lymphocyte attenuator gene and type 1 diabetes mellitus or systemic lupus erythematosus in the Japanese population. Int $\mathbf{J}$ Immunogenet 36:65-68 
Lin SC, Kuo CC, Chan CH (2006) Association of a BTLA gene polymorphism with the risk of rheumatoid arthritis. J Biomed Sci 13:853-860

M'Hidi H, Thibult ML, Chetaille B et al (2009) High expression of the inhibitory receptor BTLA in T-follicular helper cells and in B-cell small lymphocytic lymphoma/chronic lymphocytic leukemia. Am J Clin Pathol 132:589-596

Murphy KM, Nelson CA, Sedy JR (2006) Balancing co-stimulation and inhibition with BTLA and HVEM. Nat Rev Immunol 6:671-681

Nei M, Tajima F, Tateno Y (1983) Accuracy of estimated phylogenetic trees from molecular data. II. Gene frequency data. J Mol Evol 19:153-170

Nelson CA, Fremont MD, Sedy JR et al (2008) Structural determinants of herpesvirus entry mediator recognition by murine $\mathrm{B}$ and T lymphocyte attenuator. J Immunol 180:940-947

Oki M, Watanabe N, Owada T et al (2011) A functional polymorphism in $\mathrm{B}$ and $\mathrm{T}$ lymphocyte attenuator is associated with susceptibility to rheumatoid arthritis. Clin Dev Immunol 2011: 305656

Otsuki N, Kamimura Y, Hashiguchi M et al (2006) Expression and function of the B and T lymphocyte attenuator (BTLA/CD272) on human $\mathrm{T}$ cells. Biochem Biophys Res Commun 344: $1121-1127$
Ploski R, Wozniak M, Pawlowski R et al (2002) Homogeneity and distinctiveness of Polish paternal lineages revealed by $\mathrm{Y}$ chromosome microsatellite haplotype analysis. Hum Genet 110:592-600

Saitou N, Nei M (1987) The neighbor-joining method: a new method for reconstructing phylogenetic trees. Mol Biol Evol 4:406-425

Sedy JR, Gavrieli M, Potter KG et al (2005) B and T lymphocyte attenuator regulates $\mathrm{T}$ cell activation through interaction with herpesvirus entry mediator. Nat Immunol 6:90-98

Shi YY, He L (2005) SHEsis, a powerful software platform for analyses of linkage disequilibrium, haplotype construction, and genetic association at polymorphism loci. Cell Res 15:97-98

Shui JW, Steinberg MW, Kronenberg M (2011) Regulation of inflammation, autoimmunity, and infection immunity by HVEMBTLA signaling. J Leukoc Biol 89:517-523

Takezaki N, Nei M, Tamura K (2010) POPTREE2: software for constructing population trees from allele frequency data and computing other population statistics with Windows interface. Mol Biol Evol 27:747-752

Watanabe N, Gavrieli M, Sedy JR et al (2003) BTLA is a lymphocyte inhibitory receptor with similarities to CTLA-4 and PD-1. Nat Immunol 4:670-679 